\title{
The letter span in space and time
}

JAMES W. MATHEWSON, JR. ${ }^{1}$ AND JOHN C. MILLER, JR., DUKE UNIVERSITY, AND HERBERT F. CROVITZ, DURHAM V. A. HOSPITAL, Durham, N. C. 27705

The Ss had to report as many as they could of eight letters which were arranged in a line or a circle around the fixation point and which were flashed for a duration of 20 or $120 \mathrm{msec}$. The $S \mathrm{~s}$ were not told which arrangement of letters or duration of exposure would occur on any trial. The likelihood that a given letter will be reported depends on time and on the position it has in the particular configuration of which it is a part, but does not significantly depend on an interaction of position and exposure duration.

When a string of letters is flashed. Ss systematically report letters from some positions and ignore letters from other positions (Bryden, 1966; Crovitz \& Schiffman, 1965; Harcum \& Jones. 1962). The reportability of a letter depends very little on its location on the retinal projection surface and depends a great deal on its position relative to other letters in the string of which it is a part, and on the shape of the string of letters (Crovitz \& Friedman. 1967).

Bryden (1966) varied exposure duration and found a nonsignificant trend for accuracy to be relatively better at positions near the fixation point at very short exposure durations. An interaction between letter-position and exposure-time was sought in the present study in which strings of eight letters arranged in lines and circles were shown for 20 and $120 \mathrm{msec}$ with line and circle strings intermixed.

Method. Twenty Duke undergraduates served as Ss in partial fulfillment of a class requirement. Stimujus cards were prepared by mounting black English capital letters (Prestype KB 24 point) on 5 in. $x 7$ in. white cards. prepared for use in a Scientific Prototype Model GB three-channel tachistoscope. Each of the 40 stimulus cards contained eight letters. For 20 cards the lettcrs were arranged in a line $3.5 \mathrm{in}$. long with equal spaces between adjacent letters: for the other 20 cards the letters were arranged in a circle of $2.5 \mathrm{in}$. diameter with equal spaces between adjacent letters. When presented in the tachistoscope at a viewing distance of 42-75 in., the lines subtended $4 \mathrm{deg} 40 \mathrm{~min}$ and the circies subtended $3 \mathrm{deg} 20 \mathrm{~min}$ of visual angle. Each letter stood $.36 \mathrm{in}$. high and subtended $22 \mathrm{~min}$ of visual angle. The lines and the circles were aligned with the pre-exposure fixation point, a faint pencil dot at the center of a white card, so that in every case the fixation point was in the center of the string of letters. In order to increase discriminability, 15 of the possible 26 letters were used: B, D, F, G, H, K, N, Q, R, S, T, V, X, Y, and Z.

There were four stimulus conditions: lines and circles, each at 20 and 120 msec exposure duration. Thus, 10 cards were presented in each condition of spatial arrangement of letters and exposure time. The randomized sequence of stimulus cards was the same for every $\mathrm{S}$, with no more than two circles or two lines in sequence. The sequence of exposure times was different for every S. with eviry stimulus card in the pack shown at each of the two exposure durations an equal number of times.

The $S$ was instructed to fixate the fixation dot until the letters appeared. and then to orally report the letters he had seen.

Results and Discussion. The distribution of correct reports of letters by position in the stimulus and exposure duration is shown in Figs. 1 and 2 lor letters arranged in lines and circles. respectively. Consider Fig. 1. At 20 and at $120 \mathrm{msec}$ the leftmost. rightmost. and middle letters are reported more accurately than letters in the other positions in both cases. The interaction between position and exposure duration was not significant $(F=$ 2.96 , df $=7 / 133)$. The main effects of exposure duration and position of letters within the string were significant beyond the $1 \%$ level $\left(\mathrm{F}=14.93, \mathrm{~d} f^{\circ}=7 / 133\right.$; and $\left.\mathrm{F}=7.44, \mathrm{df}=1 / 133\right)$ for letter position and exposure time, respectively.

Similarly, in Fig. 2, the circles, the upper positions were reported best at both 20 and $120 \mathrm{msec}$, and analysis of variance again showed the interaction between position and time to be not significant $(\mathrm{F}=1.03 \mathrm{df}=7 / 133)$ while the main effects of timc and position were again significant at beyond the $1 \%$ level $(\mathrm{F}=$ 14.93 , $\mathrm{df}=7 / 133$, and $F=7.44$, $\mathrm{df}=1 / 133$ ) for letter position and exposure time, respectively. Thus for both stimulus configurations. the effect of shortening exposure duration from 120 to $20 \mathrm{msec}$ was to impair accuracy of report somewhat, but, like Bryden, we found the interaction of time with position not to be significant. Yet, trends exist in our data, as they did in his, in the direction of such an interaction, and other evidence does rather clearly exist that shows that allowing more time broadens the effective tachistoscopic field (Chaiken, Corbin, \& Volkmann. 1962: Mackwortl, 1965).

The distribution of accuracy shown in Fig. 2 seems entirely compatible with the results of Crovitz \& Friedman (1967). In that study letters were presented on the circumference of closed curves with no strings arranged in lines shown in the experiment. In that study Ss were set for nonlinear strings: in the present study such set was reduced by the presentation of letter lines, but there was no apparent effect of reduced set on the distribution of reports. This contrasts with the finding that set with regard to where on the horizontal meridian a letter line will appear does affect report (Crovitz, Schiffman. Lipscomb, Posnick, Rees, Schaub, \& Tripp, 1966). Another well-known situation that highlights the complex relevance of set to report is the study of Lawrence \& Coles (1954). No clear integration of this complex problem is suggested by the present results.

Bryden (1966) suggested that longer durations allow perception of more peripheral parts of the visual field. If letters are processed sequentially as some function of position. the ordinary letter-span paradigm in which all letters are presented simultaneously would bear on studies in which letters are presented sequentially as some function of location. Mayzner. Tresselt, \& Helfer (1967) conclude from such studies that "if the time span is very short. that is in the range from 0 to $20 \mathrm{msec}$ approximately, input trains are processed as a single package. However, as the time span enters a critical

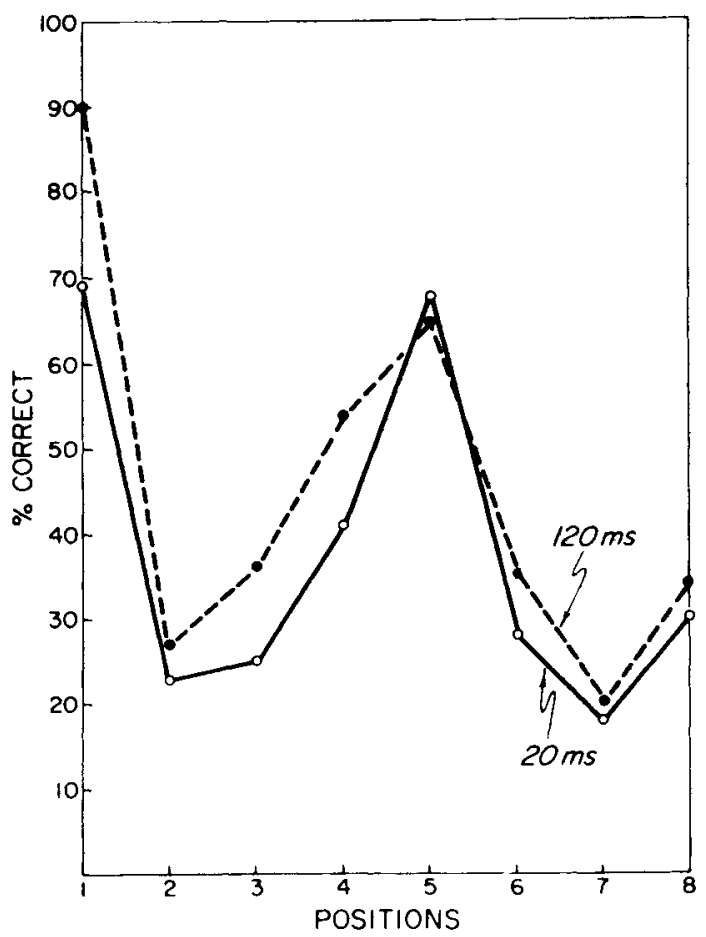

Fig. 1. Percentage of letters presented in the eight positions in line-stimuli which were correctly reported (Position 1 is the leftmost letter-position). 


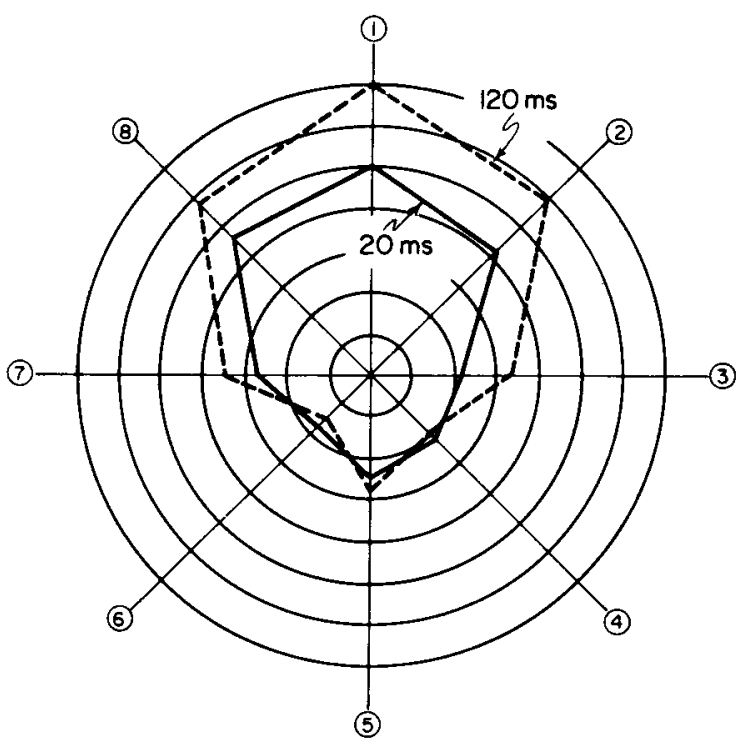

Fig. 2. Percentage of letters presented in the eight positions in circle-stimuli which were correctly reported (Position 1 is the top letter-position; each division on the polar coordinate graph represents $10 \%$ ).

range from 100 to $300 \mathrm{msec}$ approximately, very complicated interactions between time and space begin to occur..." Detailed analysis of the relevance of simultaneous and sequential presentation of letters arranged in some pattern to the problems of metacontrast need to be made (Kahneman, 1967). Julesz (1964) found that sequential presentation of parts of a pattern is easier to perceive than any aiternative, but whether this is true for letters presented in some spatial arrangement remains unknown.

\section{REFERENCES}

BRYDEN, M. P. Accuracy and order of report in tachistoscopic recognition. Canad. J. Psychol.., 1966, 20, 262-272.

CHAIKEN, JOYCE D., CORBIN, H. H., \& VOLKMANN, J. Mapping a field of short-time visual search. Science, 1962, 138, 1327-1328.

CROVITZ, H. F., \& FRIEDMAN, L. A. Configurational letter spans. J. exp. Psychol, 1967, 73, 628-629.

CROVITZ, H. F., \& SCHIFFMAN, H. R. Visual field and the letter span. $J$. exp. Psychol., 1965, 70, 218-223.

CROVITZ, H. F., SCHIFFMAN, H., LIPSCOMB, D. B., POSNICK, G., REES, J., SCHAUB, R., \& TRIPP, R. Identification and localization in the letter span. Canad. J. Psychol., 1966, 20, 455-461.

HARCUM, E. R., \& JONES, M. L. Letter recognition within words flashed left and right of fixation. Science, 1962, 138, 444-445.

JULESZ, B. Some recent studies in vision relevant to form perception. Bell. Tel. Lab. Rep., 1964.

KAHNEMAN, D. An onset-onset law for one case of apparent motion and metacontrast. Percept. \& Psychophys., 1967, 2, 577-584.

LAWRENCE, D. H., \& COLES, G. R. Accuracy of recognition with alternatives before and after the stimulus. J. exp. Psychol., 1954, 47, 208-214.

MACKWORTH, N. M. Visual noise causes tunnel vision. Psychon. Sci., 1965, 3, 67-68.

MAYZNER, M. S., TRESSELT, M. E., \& HELFER, M. S. A provisional model of visual information processing with sequential inputs. Psychonomic Monogr. Suppl. 1967, 2, No. 7 (Whole No. 23).

\section{NOTE}

